\title{
RETRACTED ARTICLE: Optimal Hop Selection Based Novel Trust Based DDoS Attack Removal Framework for Reliable and Secured Transmission of Data in VANETs
}

\author{
Prabakeran Saravanan $^{1} \cdot$ T. Sethukarasi ${ }^{2}$ \\ Published online: 29 April 2019 \\ (c) Springer Science+Business Media, LLC, part of Springer Nature 2020
}

The Editor-in-Chief has retracted this article [1] because it shows significant overlap with a previously published article without proper acknowledgement [2]. This article is therefore redundant. Prabakeran Saravanan does not agree to this retraction. T. Sethukarasi has not responded to any correspondence from the editor/publisher about this retraction.

The online version of this article contains the full text of the retracted article as electronic supplementary material.

[1] Saravanan, P. \& Sethukarasi, T. Wireless Pers Commun (2019). https://doi. org/10.1007/s11277-019-06385-z

[2] Kerrache, C. A., Lagraa, N., Calafate, C. T. \& Lakas, A. Vehic Commun (2017). https://doi.org/10.1016/j.vehcom.2016.11.010

Publisher's Note Springer Nature remains neutral with regard to jurisdictional claims in published maps and institutional affiliations.

Electronic supplementary material The online version of this article (https://doi.org/10.1007/s1127 7-019-06385-z) contains the full text of the retracted article as electronic supplementary material.

Prabakeran Saravanan

prabakerans@gmail.com; prabakeranvecme@gmail.com

1 Department of CSE, KCG College of Technology, Karapakkam, Tamilnadu, India

2 Department of CSE, RMK Engineering College, Chennai, Tamilnadu, India 